\title{
Plasticity in lunar timing of larval release of two brooding pocilloporid corals in an internal tide-induced upwelling reef
}

\author{
Tung-Yung Fan ${ }^{1,2, *}$, Yu-Chieh Hsieh ${ }^{2}$, Ke-Han Lin ${ }^{3}$, Fu-Wen Kuo ${ }^{1}$, Keryea Soong ${ }^{3}$, \\ Crystal J. McRae ${ }^{4}$, Peter J. Edmunds ${ }^{5}$, Lee-Shing Fang ${ }^{6}$ \\ ${ }^{1}$ National Museum of Marine Biology and Aquarium, Pingtung, Taiwan 944, ROC \\ ${ }^{2}$ Institute of Marine Biology, National Dong Hwa University, Pingtung, Taiwan 944, ROC \\ ${ }^{3}$ Department of Oceanography, National Sun Yat-Sen University, Kaohsiung, Taiwan 804, ROC \\ ${ }^{4}$ Department of Natural Resources and Environmental Studies, National Dong Hwa University, Hualien, Taiwan 974, ROC \\ ${ }^{5}$ Department of Biology, California State University, Northridge, California 91330-8303, USA \\ ${ }^{6}$ Department of Leisure and Sports Management, Cheng Shiu University, Kaohsiung, Taiwan 833, ROC
}

\begin{abstract}
The environmental conditions in shallow marine environments vary on multiple temporal scales, but under the influence of climate change, these conditions are likely to change in frequency and magnitude. Phenotypic plasticity is one mechanism by which organisms can respond to this complex environmental challenge. Plasticity of reproductive timing may have beneficial value, especially for species that reproduce multiple times annually. In this study, we quantified the lunar periodicity of larval release by 2 brooding reef corals, Pocillopora damicornis and Seriatopora hystrix, in Nanwan Bay, southern Taiwan, from 2003 to 2008. Larval release was highly synchronized for both species, with lunar timing of monthly larval release varying among tidal phases, seasons and years that differed in seawater temperature. Lunar date of peak larval release for both species was related non-linearly to mean monthly seawater temperature, with release day advancing as temperature increased from winter $\left(23^{\circ} \mathrm{C}\right)$ to summer $\left(28^{\circ} \mathrm{C}\right)$. In the winter, peak release of larvae mainly occurred after the first quarter moon, with occasional larval release after the full moon, but in the summer, peak larval release occurred around the first quarter moon and neap tide. Since Nanwan Bay is strongly affected by intermittent upwelling induced by internal tides, the shift in reproductive timing may allow larvae released in the summer to avoid the negative thermal effects of upwelling and may also favor local retention.
\end{abstract}

KEY WORDS: Larval release $\cdot$ Lunar periodicity $\cdot$ Plasticity $\cdot$ Seawater temperature $\cdot$ Pocillopora damicornis $\cdot$ Seriatopora hystrix $\cdot$ Upwelling

\section{INTRODUCTION}

Reproductive timing of marine benthic organisms has a profound influence on offspring survival, dispersal, settlement, and recruitment, and thus plays an important role in determining reproductive success (Harrison \& Wallace 1990, Richmond \& Hunter 1990, Morgan \& Christy 1994, Morgan 1996, Carson et al. 2010, Christy 2011). Reproductive timing has been correlated with several environmental factors

\footnotetext{
${ }^{*}$ Corresponding author: tyfan@nmmba.gov.tw
}

at different temporal scales, including seasonal cycles of temperature and solar irradiance, lunar periodicity of the tide and moon, as well as the diel cycle of light-dark (Harrison \& Wallace 1990, Richmond \& Hunter 1990, Baird et al. 2009, Harrison 2011, Kerr et al. 2012), which may provide cues to the occurrence of environmental conditions favored for reproductive success. Therefore, data on reproductive timing is valuable in order to better understand the ways in which organisms respond to envi-

() The authors 2017. Open Access under Creative Commons by Attribution Licence. Use, distribution and reproduction are unrestricted. Authors and original publication must be credited. 
ronmental conditions, their population dynamics, and the capacity of communities to recover following disturbances.

Marine environmental conditions vary temporally, and are becoming increasingly extreme and fluctuating more under the impact of climate change, such as the occurrence of abnormally warm or cold events (Hoegh-Guldberg 1999, Hoegh-Guldberg et al. 2007, Moore et al. 2011, Rivest \& Gouhier 2015). Phenotypic plasticity is one mechanism by which organisms can respond to these environmental challenges (Byrne 2011, Cumbo et al. 2013, Reusch 2014). Plasticity of reproductive timing may be especially beneficial for species that reproduce multiple times annually by enabling the release of offspring during favorable conditions at different times of the year. Such plasticity has been demonstrated in various marine benthic organisms, such as crabs (Morgan \& Christy 1994, Morgan 1996, Kerr et al. 2012, Kerr 2015) and corals (Jokiel et al. 1985, Fan \& Dai 1999, Lin et al. 2013, Crowder et al. 2014).

Upwelling, in its various forms, can affect the reproductive activities of marine benthic invertebrates. Seasonal wind-driven upwelling, for example, can impede coral reproduction (Glynn et al. 1991, 2012), weaken synchrony in the timing of larval release of crabs (Morgan et al. 2011), and delay larval release timing of fiddler crabs (Kerr et al. 2012, Kerr 2015). In contrast, little is known about the effects of intermittent upwelling induced by internal tides on reproduction. Intermittent upwelling, however, can enhance coral growth (Leichter \& Genovese 2006), increase energy reserves (Roder et al. 2010), and enable metabolic plasticity (Roder et al. 2011) to confer resistance and resilience to environmental conditions, resulting in both adults and larvae being physiologically well suited to fluctuating temperature regimes (Putnam et al. 2010, Mayfield et al. 2013).

The brooding coral species Pocillopora damicornis and Seriatopora hystrix are common Indo-Pacific pocilloporid corals. They conduct internal fertilization and release buoyant planktonic larvae which may disperse widely or settle quickly (Harrison \& Wallace 1990, Richmond \& Hunter 1990, Fan et al. 2002, 2006, Villanueva et al. 2008). Larval release in these species is synchronized to the lunar phase and occurs throughout the year at low latitudes and seasonally at high latitudes (Harriott 1983, Richmond \& Jokiel 1984, Tanner 1996, Fan et al. 2002, Villanueva et al. 2008). Typically, the lunar timing of larval release of brooding coral species at a single location is highly consistent with a specific moon or tidal phase, although this timing varies among biogeographic regions (Richmond \& Hunter 1990, Villanueva et al. 2008, Baird et al. 2009, Harrison 2011).

The correlation between lunar timing of larval release and tidal phase suggests that ecological significance lies in either maximizing larval dispersal during spring tide or larval retention and local recruitment during neap tide (Tanner 1996, Fan et al. 2002, Villanueva et al. 2008, Harrison 2011). The lunar cycle of tidal and moon phases may be the major proximate environmental factor controlling the lunar periodicity of larval release. However, synchronization in timing may not be fixed; for example, the timing of larval release of $P$. damicornis in Hawaii is plastic and can be controlled by low light intensities occurring at night (Jokiel et al. 1985), while that of P. damicornis in southern Taiwan can be changed by manipulation of seawater temperature (Crowder et al. 2014). Differences in lunar timing of larval release among allopatric populations likely represent adaptations to local environmental conditions and cues (Harrison \& Wallace 1990, Richmond \& Hunter 1990, Baird et al. 2009, Harrison 2011).

$P$. damicornis and $S$. hystrix are common on the fringing reef of Nanwan Bay, southern Taiwan, where they reproduce monthly (Dai et al. 1992, Fan et al. 2002). The environmental conditions in this region show seasonal and lunar variations due to several physical factors including currents, tides, internal tide-induced upwelling, monsoons, and typhoons (Lee et al. 1997, Jan et al. 2004, Jan \& Chen 2009, Rivest \& Gouhier 2015, Ashkenazy et al. 2016). In winter, Nanwan Bay is affected by the northeast monsoon, and the mean seawater temperature is $\sim 23^{\circ} \mathrm{C}$ with daily perturbations of 1 to $2^{\circ} \mathrm{C}$; in summer, mean seawater temperature is $\sim 28^{\circ} \mathrm{C}$ with perturbations of 2 to $10^{\circ} \mathrm{C}$ for several hours during spring tide caused by strong internal tide-induced upwelling (Lee et al. 1997, Jan \& Chen 2009). The seasonal and lunar variation of the marine environment in southern Taiwan may influence the temporal pattern of larval release from brooding corals, especially for species that reproduce multiple times annually.

In this study, we examined the lunar periodicity of larval release for $P$. damicornis and $S$. hystrix monthly in Nanwan Bay in 2003 (throughout the entire year) and in 2005, 2007, and 2008 (for 5 to 9 mo). Our objectives were (1) to test the hypothesis that the lunar timing of peak larval release occurs around the quarter moon and the neap tide; and (2) to test for a relationship between lunar timing of larval release and seawater temperature. Based on the results of our analyses, we explore the plasticity potential of reproductive timing in corals on a reef influenced by 
internal-tide induced upwelling, with a particular interest in the implications for the avoidance of strong upwelling in summer.

\section{MATERIALS AND METHODS}

\section{Coral collection and study site}

The timing of larval release from colonies of Pocillopora damicornis and Seriatopora hystrix was determined in an aquarium system using colonies freshly collected from nearby reefs ( 3 to $8 \mathrm{~m}$ depth) in Nanwan Bay, southern Taiwan. Both species are common on these reefs, where numerous discrete colonies with roughly hemispherical morphologies can be found. Colonies of $P$. damicornis (8 to $18 \mathrm{~cm}$ diameter) and $S$. hystrix ( 7 to $27 \mathrm{~cm}$ diameter) were collected from Hobihu reef $\left(21^{\circ} 56^{\prime} 29^{\prime \prime} \mathrm{N}, 120^{\circ} 44^{\prime} 70^{\prime \prime} \mathrm{E}\right)$ in 2003 , 2005, 2007, and 2008, and additional colonies of $S$. hystrix were collected from Outlet reef $\left(21^{\circ} 55^{\prime} 89^{\prime \prime} \mathrm{N}\right.$, $120^{\circ} 45^{\prime} 69^{\prime \prime}$ E; $1 \mathrm{~km}$ south of Hobihu) in 2003, 2005, and 2007 due to a limited number of colonies at Hobihu (see Tables 1 \& 2).

Each lunar month, 3 to 8 colonies of each species were collected from the reef using a hammer and chisel. Freshly collected colonies were immediately transported to the National Museum of Marine Biology and Aquarium (Pingtung, Taiwan) where the timing of larval release was studied with the colonies housed in flow-through aquaria. The use of an aquarium system to study larval release allowed for a more detailed examination than would be possible in situ, particularly in recording the day and time of larval release throughout the year. The timing of larval release from corals in aquaria and in situ is similar as long as the physical conditions in the aquaria adequately match those in the field (Richmond \& Jokiel 1984, Fan et al. 2002, 2006, Villanueva et al. 2008).

\section{Larval collection}

Each colony was placed in a separate tank (6 l) that was maintained in an outdoor facility and exposed to a natural photoperiod and ambient seawater temperature, with seawater (supplied at $11 \mathrm{~min}^{-1}$ ) pumped directly from a near-shore location (5 $\mathrm{m}$ depth) and sand-filtered $(\sim 50 \mu \mathrm{m})$. The outflow of each tank trickled through a collecting cup fitted with $100 \mu \mathrm{m}$ mesh to retain the larvae, which typically ranged in length from 500 to $1200 \mu \mathrm{m}$. The number of larvae released by each colony was counted daily at $\sim 09: 00 \mathrm{~h}$, since these 2 species release the majority of their larvae before dawn (Fan et al. 2006). Colonies were replaced with new corals freshly collected from the study reefs at the end of each lunar month to ensure (1) that the timing of larval release reflected in situ release, (2) that colonies did not acclimate to the aquarium conditions, and (3) to confirm that colonies were independent statistical replicates among lunar months.

The comparison of periodicity of larval release among different months and years was expressed using a lunar calendar instead of a solar calendar because the lunar month is most strongly correlated with the tidal phases. Only colonies that retained the same coloration of freshly collected corals (i.e. that were 'healthy') and released $>20$ larvae within a lunar month were used for analyses. To quantify the lunar periodicity of larval release, using colonies as replicates, the timing of release relative to the lunar month was expressed in degrees on a $360^{\circ}$ scale. Circular statistics were used to calculate the central tendency (a mean angle) and a measure of dispersion (angular deviation) of larval release dates for the sampled colonies (Zar 1999). Rayleigh tests were used to test the null hypothesis that larvae were released uniformly throughout the lunar month. If the null hypothesis was rejected, the mean lunar day (MLD) of larval release for each colony was used to describe the synchronization of larval release for that lunar month (Tanner 1996, Fan et al. 2002, Villanueva et al. 2008, Crowder et al. 2014). Seasonal variations in the timing of larval release were analyzed using the parametric Watson Williams test. The year was divided into warm (April to September) and cold (January to March and October to December) seasons. All analyses were conducted using RStudio (version 1.0.44).

To relate the timing of larval release to the in situ thermal environment, seawater temperature was recorded $1 \mathrm{~km}$ north of the Hobihu study reef using a HOBO XT temperature logger (Onset Computer) (accuracy: $\pm 0.2^{\circ} \mathrm{C}$ ) that was attached to the reef at $5 \mathrm{~m}$ depth. This logger recorded seawater temperature at $1 \mathrm{~h}$ intervals throughout the year, thus ensuring that the temperature conditions the study corals were exposed to prior to collection were known. Seawater temperature was averaged by day, and daily values were used to calculate mean temperature for each lunar month. For each species, the relationship between mean lunar day of larval release and mean monthly seawater temperature was analyzed for data pooled among study years using least squares regression. Akaike's information criterion (AIC) was used to determine which function best described the relationship (O'Connor et al. 2007). 


\section{RESULTS}

All colonies of Pocillopora damicornis and Seriatopora hystrix released larvae on monthly lunar cycles (Figs. 1-4). Seasonality in larval output occurred in both species, with the mean number of larvae released per colony per month being low in winter (lunar November to January; 239 to 910 for P. damicornis and 31 to 1260 for S. hystrix), but high in summer (lunar June to August; 1143 to 4092 for P. damicornis and 345 to 1915 for $S$. hystrix) (Tables $1 \& 2$ ).

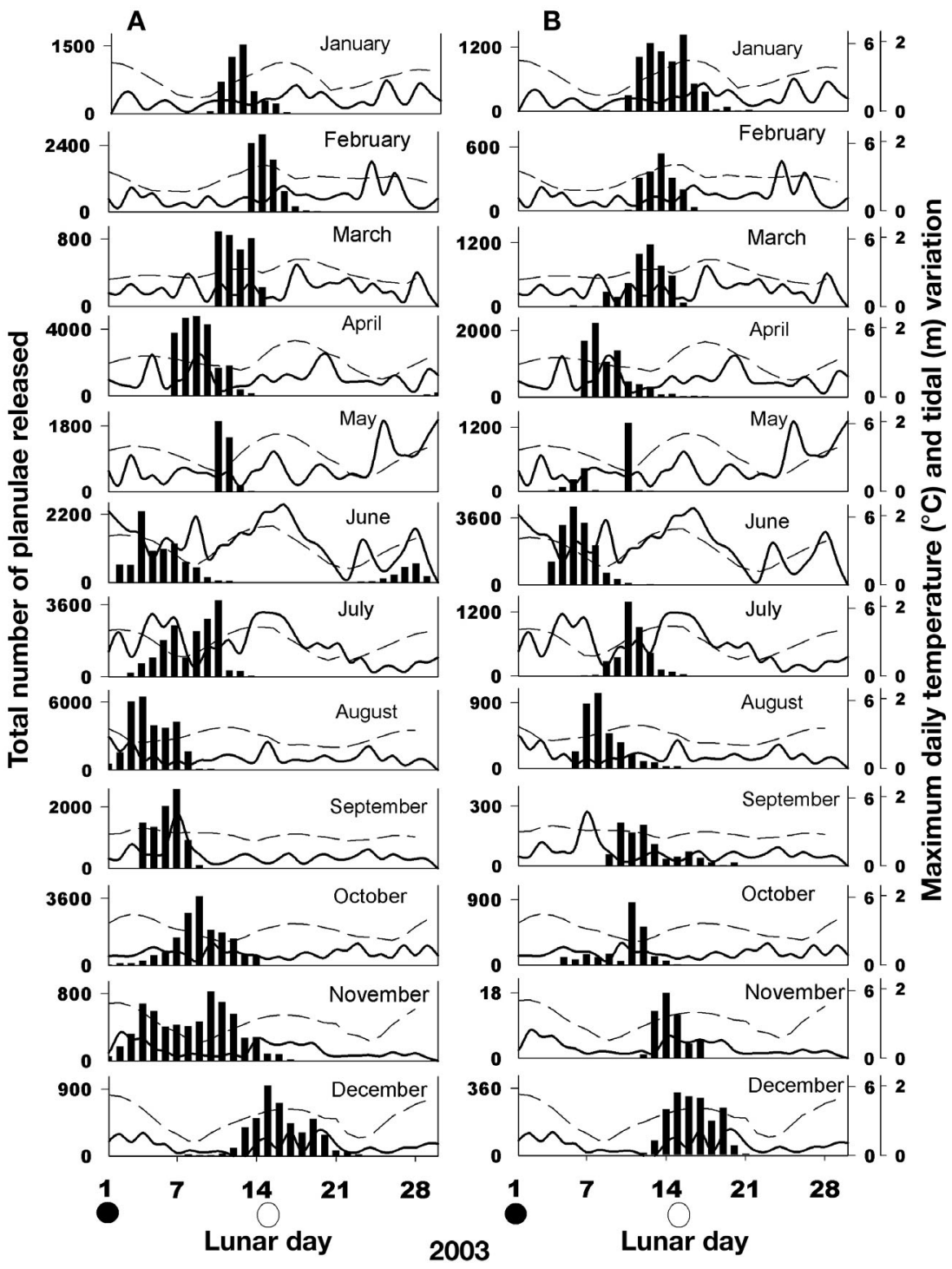

Fig. 1. Daily variation in the total number of larvae released, seawater temperature, and tidal amplitude per day in each lunar month in 2003 for (A) Pocillopora damicornis and (B) Seriatopora hystrix. Time (abscissa) is expressed as days in each lunar month relative to the new moon (filled circle, lunar day 1) and full moon (open circle). Note that the ordinates for larval release differ among lunar months. Maximum variation in daily seawater temperature ( 0 to $6^{\circ} \mathrm{C}$ ): solid line; tidal amplitude (0 to $2 \mathrm{~m}$ ): dashed line
Both species showed tight synchronization of larval release with respect to lunar phase (Rayleigh's test, $\mathrm{p}<0.001$ for all tests; Tables $1 \& 2$ ) throughout all 4 study years. The lunar phase upon which this synchronization was based varied among lunar months, tidal phases, seasons, and years.

The peak larval release of $P$. damicornis occurred around the first quarter moon in most study months (MLD 4.0 to 13.7 during lunar January to November in 2003, 5.0 to 11.5 during lunar March to July in 2005, 6.8 to 12.1 during lunar February to December in 2007 , and 4.5 to 11.8 during lunar January to June in 2008), while it occurred around full moon in lunar December 2003 (MLD 15.2) and lunar February 2005 (MLD 19.4) (Table 1, Figs. 1A4A). The MLD of larval release was significantly different between warm and cold seasons in each of the $4 \mathrm{yr}$ (Watson Williams test, $F=33.83$ to 175.34, $\mathrm{df}=1,21$ to $1,91, \mathrm{p}<0.001$ ).

The peak larval release for $S$. hystrix occurred around the first quarter moon in most study months (MLD 5.8 to 13.7 during lunar January to October in 2003, 8.9 to 11.8 during lunar May to July 2005, 7.1 to 12.5 during lunar February to December 2007, and 6.4 to 13.5 during lunar January to June 2008), while it occurred around the full moon during lunar November to December in 2003 (MLD 14.4 to 17.0) and after the full moon (MLD 15.3 to 21.8) during lunar January to March in 2005 (Table 2, Figs. 1B-4B). The MLD of larval release was significantly different between warm and cold seasons in 2003 (Watson Williams test, $F=71.93, \mathrm{df}=1,81, \mathrm{p}<0.001$ ).

Overall, in winter the peak release of larvae for both species occurred just after the first quarter moon with occasional release after full moon, but in summer it shifted to around the first quarter moon. On the other hand, lunar patterns of larval release for both species were independent of the tidal cycle because they showed no temporal relationship to the maximum daily tidal variation in 2003 (Fig. 1).

Maximum daily temperature variation was low and ranged between 2.0 and $3.7^{\circ} \mathrm{C}$ in winter (lunar December 


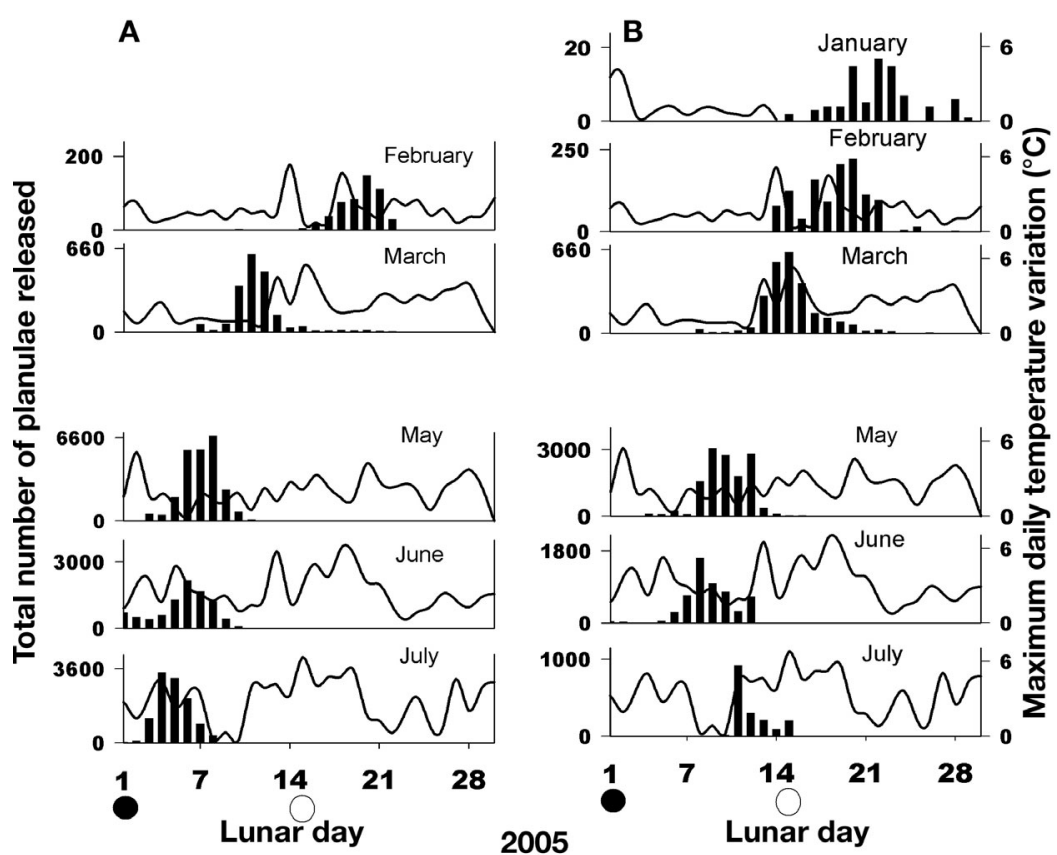

Fig. 2. Daily variation in the total number of larvae released and seawater temperature per day in each lunar month in 2005 for (A) Pocillopora damicornis and (B) Seriatopora hystrix. For further details, see Fig. 1

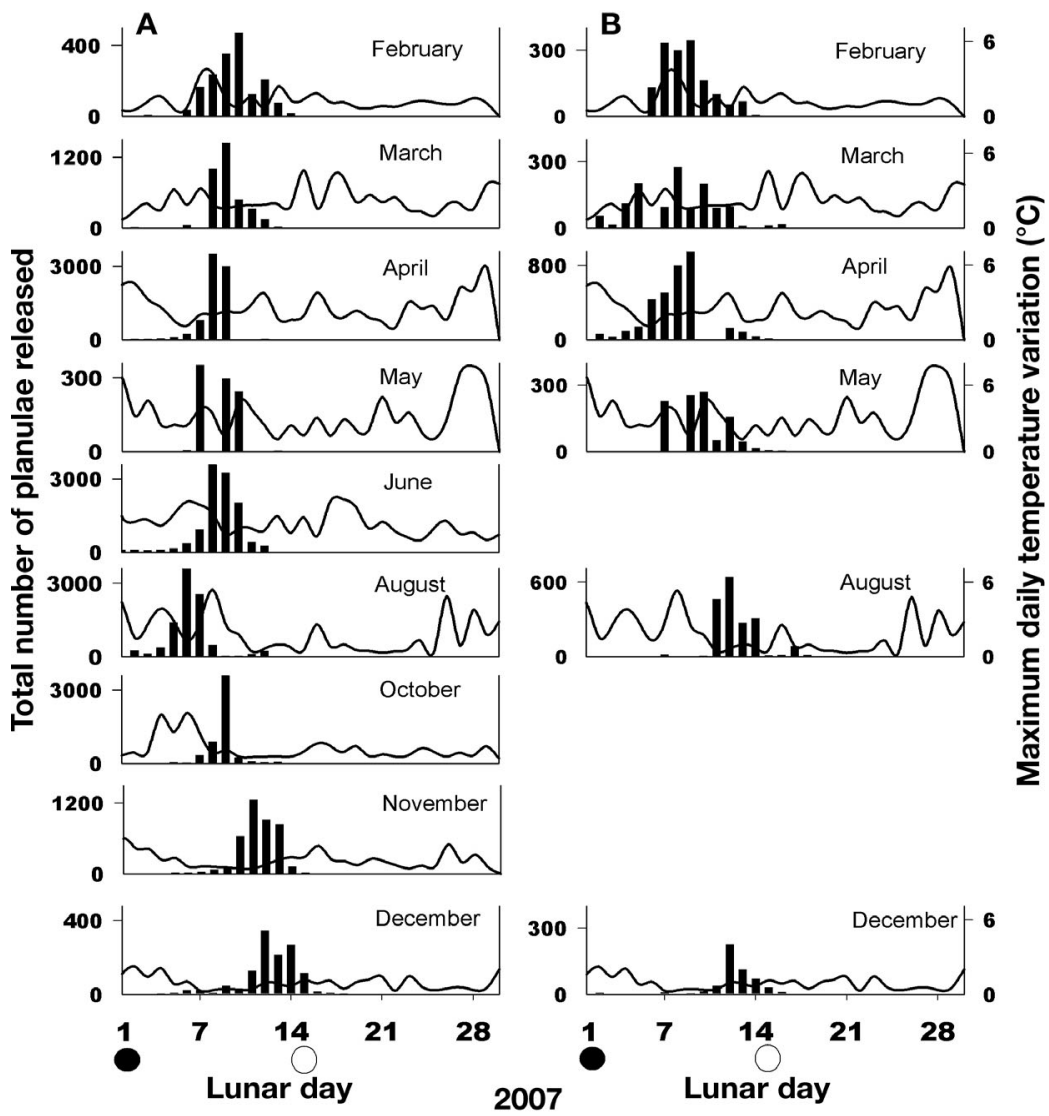

Fig. 3. Daily variation in the total number of larvae released and seawater temperature per day in each lunar month in 2007 for (A) Pocillopora damicornis and (B) Seriatopora hystrix. For further details, see Fig. 1 and January), but was high and ranged between 4.2 and $7.7^{\circ} \mathrm{C}$ in summer (lunar May to July) (Figs. 1-4). For 32 mo over 4 yr in which larval release was recorded, the peak of larval release and maximum daily temperature variation in $P$. damicornis and $S$. hystrix was separated in 31 and $30 \mathrm{mo}$, but overlapped only in 1 (September 2003) and 2 mo (March 2005 and February 2007), respectively. Thus, peak larval release in both species most likely avoided the peak of maximum daily temperature variation, especially in summer.

Mean monthly seawater temperature measured at a depth of $5 \mathrm{~m}$ in Nanwan Bay showed variation among lunar months, seasons, and years (Fig. 5). In general, temperatures were lowest (22.7 to $\left.25.2^{\circ} \mathrm{C}\right)$ during lunar January and December and highest (27.3 to $29.4^{\circ} \mathrm{C}$ ) during lunar May to August. Monthly mean temperature for lunar January and February was lowest in 2005 (22.7 and $23.1^{\circ} \mathrm{C}$, respectively) and highest in 2007 (25.1 and $25.9^{\circ} \mathrm{C}$, respectively). Monthly mean and daily maximum temperatures were unusually high in 2007 during lunar May (29.0 and $30.5^{\circ} \mathrm{C}$, respectively) and June (29.4 and $30.7^{\circ} \mathrm{C}$, respectively) compared to any other time in the study (Figs. 3 \& 5).

In lunar January and February 2005, when monthly mean seawater temperature (MMST) was coldest (Fig. 5), peak larval release for both species occurred latest (MLD 18.9 to 21.8; Tables $1 \& 2$, Fig. 6). The MLD of larval release was significantly different between February 2005 (MLD 19.4) and February 2007 (MLD 9.5) for P. damicornis (Watson Williams test, $F=5.31$, $\mathrm{df}=1,14, \mathrm{p}=0.037$ ). In contrast, in lunar May and June 2007, although MMST was unusually high, the MLD of larval release for both species occurred close to the first quarter moon (MLD 8.4 to 8.9; Tables 1 \& 2, Fig. 6).

The MLD of peak larval release was related non-linearly to MMST for both P. damicornis and S. hystrix. AIC iden- 


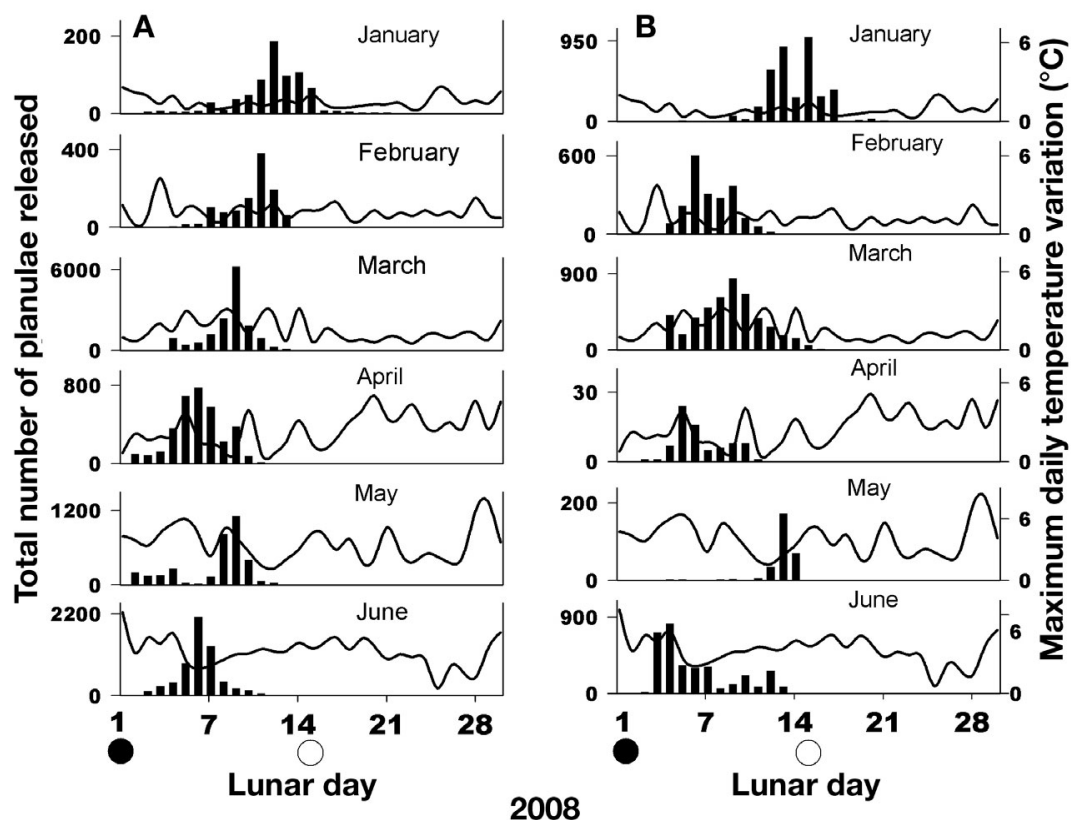

Fig. 4. Daily variation in the total number of larvae released and seawater temperature per day in each lunar month in 2008 for (A) Pocillopora damicornis and (B) Seriatopora hystrix. For further details, see Fig. 1

Seasonality of larval output occurred, with more larvae released in summer, especially at $\sim 28^{\circ} \mathrm{C}$ in both species in Nanwan Bay (MMST range: 23.0 to $28.3^{\circ} \mathrm{C}$; Edmunds et al. 2011). Higher reproductive output in summer has also been recorded for $P$. damicornis and $S$. hystrix at Heron Island in the southern Great Barrier Reef (MMST: 20.8 to $27.9^{\circ} \mathrm{C}$; Tanner 1996) and for P. damicornis at Lizard Island on the northern Great Barrier Reef (MMST: 23.8 to $29.4^{\circ} \mathrm{C}$; Harriott 1983). In contrast, patterns of relatively uniform larval output throughout the year have been reported for both species in Bolinao, northwestern Philippines (MMST: 26.9 to $30.1^{\circ} \mathrm{C}$; Villanueva et al. 2008), and for P. damicornis in Hawaii and at Enewetak Atoll (MMST: 24.3 to 26.9 and 27.6 to $29.2^{\circ} \mathrm{C}$, respectively; Richmond \& Jokiel 1984). Seasonal variation in repro-

tified power functions as the best means to describe the relationship (Fig. 6; $F=160.39$, df $=1,184$, p < $0.001, \mathrm{AIC}=100.0$ for $P$. damicornis; $F=114.60, \mathrm{df}=$ $1,121, \mathrm{p}<0.001, \mathrm{AIC}=5.9$ for $S$. hystrix). As mean seawater temperature increased from $\sim 23^{\circ} \mathrm{C}$ (winter) to $\sim 28^{\circ} \mathrm{C}$ (summer), MLD advanced from lunar day 15 or 16 (around full moon) to lunar day 7 or 8 (around first quarter moon).

\section{DISCUSSION}

Pocillopora damicornis and Seriatopora hystrix from Nanwan Bay, southern Taiwan, showed similar patterns of high synchronization in lunar periodicity of monthly larval release throughout the year, as well as in lunar timing of larval release, which was plastic and varied among tidal phases, seasons, and years. In general, peak release of larvae occurred after the first quarter moon in winter, but coincided with the first quarter moon and neap tide in summer. Lunar date of peak larval release for both species was related non-linearly to mean monthly seawater temperature, with release day advancing as temperature increased from winter $\left(23^{\circ} \mathrm{C}\right)$ to summer $\left(28^{\circ} \mathrm{C}\right)$. This seasonal shift of lunar phase timing of larval release in response to temperature is novel to all other findings on lunar periodicity of larval release in brooding corals (Harrison \& Wallace 1990, Richmond \& Hunter 1990, Baird et al. 2009, Harrison 2011). ductive output of corals is most likely related to changes in seawater temperature (Harriott 1983, Harrison \& Wallace 1990, Richmond \& Hunter 1990, Tanner 1996, McGuire 1998, Harrison 2011).

The pattern in lunar timing of larval release for $P$. damicornis and $S$. hystrix has been studied at a number of locations throughout the Indo-Pacific and typically has shown that the timing of release is constant with moon or tidal phases (Harrison \& Wallace 1990, Baird et al. 2009). For P. damicornis, the lunar timing of peak larval release is around the first quarter moon in Bolinao, northwestern Philippines (Villanueva et al. 2008), and at Enewetak Atoll (Richmond \& Jokiel 1984), as well as for B morphs of P. damicornis in Hawaii (Richmond \& Jokiel 1984), which is similar to the summer release timing in southern Taiwan. In contrast, peak larval release occurs during the second quarter moon, for example, on Heron Island in the southern Great Barrier Reef (Tanner 1996) and for Y morphs of P. damicornis in Hawaii (Richmond \& Jokiel 1984). However, larval release of $P$. damicornis at Lizard Island, Great Barrier Reef, occurs at full moon in winter and at new moon in summer, but at spring tides in both summer and winter (Harriott 1983). For $S$. hystrix, peak larval release occurs at the second quarter moon in northwestern Philippines (Villanueva et al. 2008), but mainly occurs around the first quarter moon in southern Taiwan (this study).

The association of the lunar timing of larval release with seawater temperature (Fig. 6), yet lacking con- 


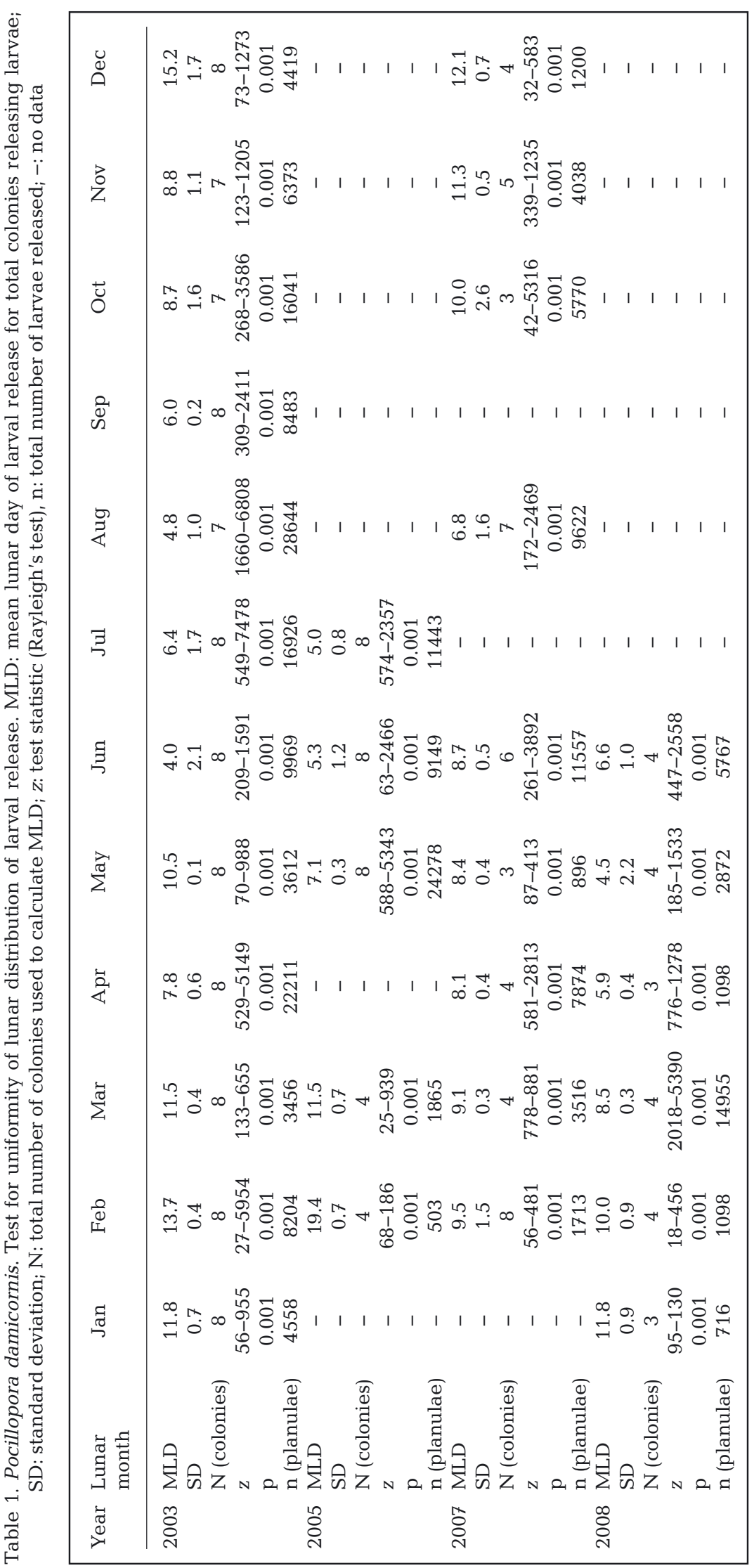

sistency with moon and tidal phase, suggests that temperature plays the most important role among these 3 factors in determining the timing of lunar periodicity of larval release in $P$. damicornis and $S$. hystrix in southern Taiwan. It is likely that seawater temperature serves as a proximate factor, with temperature increases favoring rapid development of gametes, embryos, larvae, and ultimately, advanced reproductive timing $\left(\mathrm{O}^{\prime} \mathrm{Con}-\right.$ nor et al. 2007, Moore et al. 2011). Similarly, Kerr et al. (2012) found that embryo incubation period decreased non-linearly with increasing incubation temperature in 2 fiddler crabs. However, when seawater temperature approaches an upper thermal threshold value for $P$. damicornis and S. hystrix, larval development may be constrained by physiological and biochemical mechanisms (Edmunds et al. 2011) and thus reproductive timing cannot advance further.

Although other seasonal environmental factors such as photoperiod and solar radiation may play roles in regulating the lunar timing of larval release from brooding corals, it has been demonstrated experimentally that seawater temperature alone can change the timing of lunar periodicity in larval release of $P$. damicornis from Nanwan Bay (Crowder et al. 2014). In the study by Crowder et al. (2014), the lunar timing of larval release of colonies in controlled temperature treatment tanks was changed over a single reproductive cycle. The high temperature treatment $\left(28^{\circ} \mathrm{C}\right)$ resulted in earlier larval release compared to the low temperature $\left(23^{\circ} \mathrm{C}\right)$. Similar to our results (Fig. 6), Crowder et al. (2014) found that P. damicornis larval release peaked around full moon (MLD 17.5 and 12.5 in lunar March and June) and around the first quarter moon (MLD 8.4 and 7.7 in lunar March and June) for simulated winter $\left(23^{\circ} \mathrm{C}\right)$ and summer $\left(28^{\circ} \mathrm{C}\right)$ seawater temperatures, respectively. The advancement of annual reproductive 


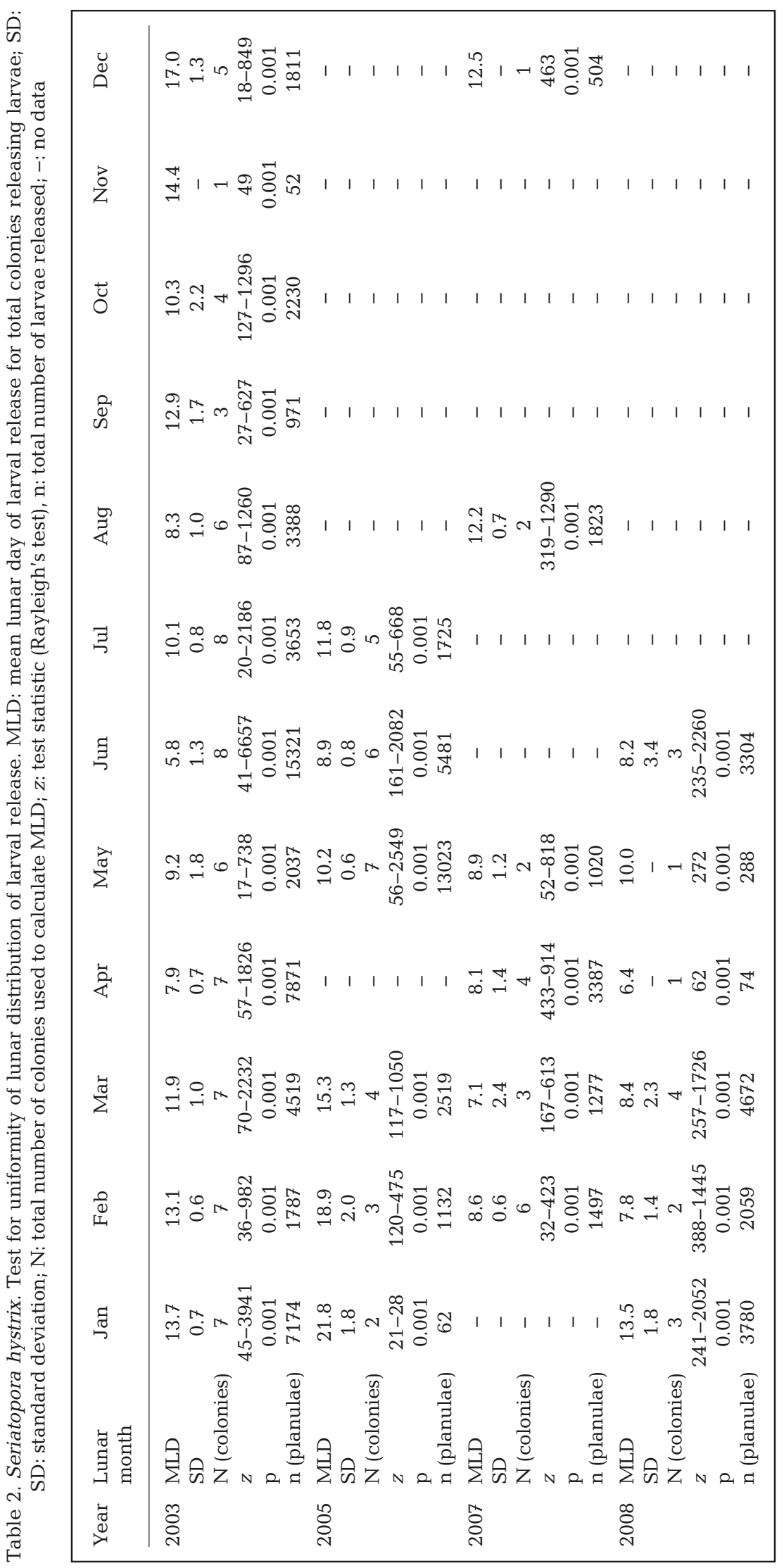

timing with increasing temperature has also been reported for the broadcast spawning coral Echinopora lamellosa, at least when it is transplanted from northern (colder) to southern (warmer) Taiwan (Fan \& Dai 1999). In addition, earlier annual coral spawning on inshore reefs in the Great Barrier Reef has been attributed to early rising seawater temperatures (Babcock et al. 1986).

The lunar timing of larval release was found to differ between $P$. damicornis and S. hystrix at Heron Island on the southern Great Barrier Reef (MLD 20.5 and 16.0 for $P$. damicornis and $S$. hystrix, respectively; Tanner 1996) and in the Philippines (MLD 10 and 25 for $P$. damicornis and $S$. hystrix, respectively; Villanueva et al. 2008). This offset in timing of larval release between these species is thought to reduce competition for settlement surfaces and promote coexistence (Villanueva et al. 2008); yet in the present study, the lunar timing of larval release from $P$. damicornis and S. hystrix was similar for colonies collected from Nanwan Bay. However, the diel periodicity of larval release differs between these species in Nanwan Bay, with $P$. damicornis releasing larvae throughout the day (usually 2 peaks; one in the early morning and one at night) and $S$. hystrix releasing larvae with high synchrony (1 peak; close to sunrise) (Fan et al. 2006).

Reproductive timing for most organisms presumably reflects adaptation to environmental conditions to optimize reproductive success (Harrison \& Wallace 1990, Baird et al. 2009). The similar seasonal variation of lunar timing of larval release in $P$. damicornis and $S$. hystrix reported herein suggests that the timing of larval release may have positive fitness consequences. It is striking that the coin- 


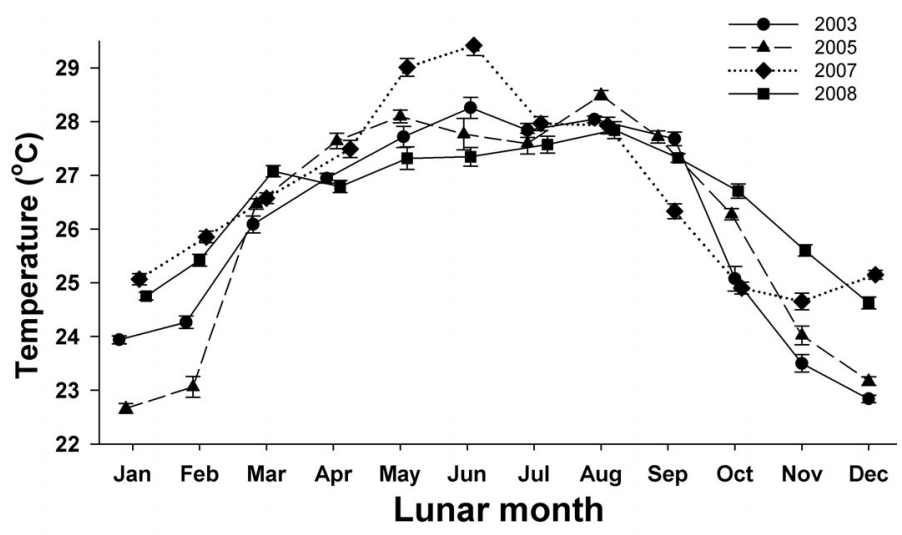

Fig. 5. Comparison among years (2003 to 2008) of monthly mean seawater temperatures measured at $5 \mathrm{~m}$ depth near the Hobihu site from which most of the corals were collected $(\mathrm{mean} \pm \mathrm{SE}, \mathrm{n}=14$ to 30$)$

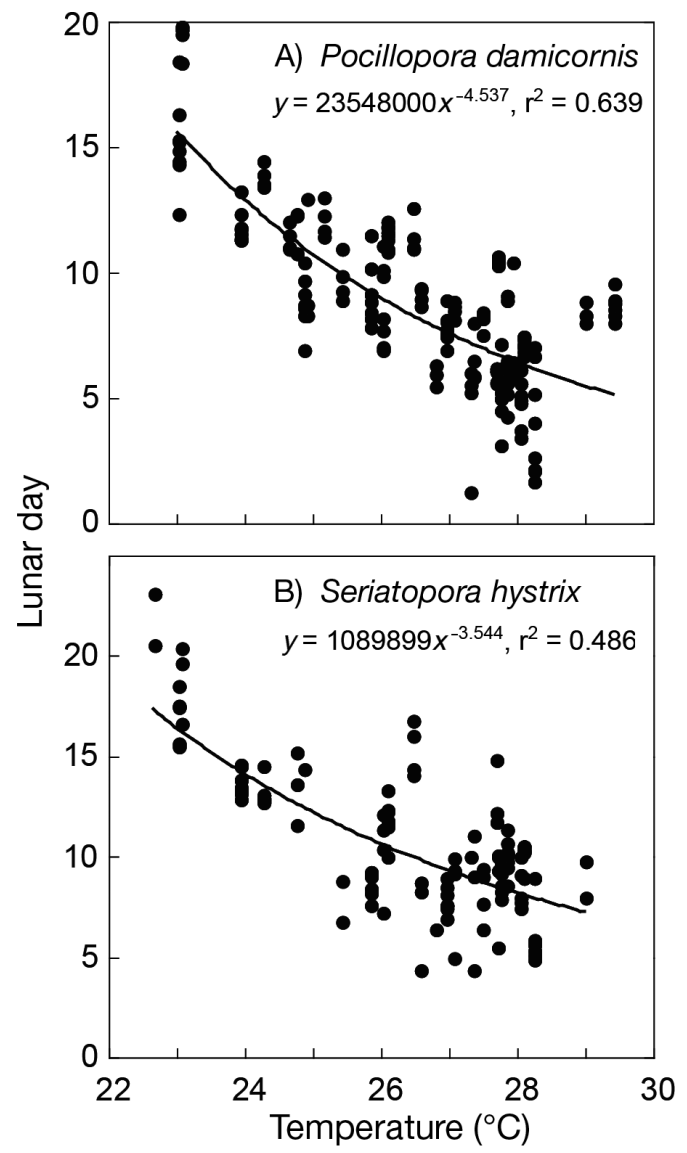

Fig. 6. Relationship between monthly mean temperature ( $\mathrm{n}=25$ to $30 \mathrm{~d} \mathrm{mo}^{-1}$ ) and mean lunar day of larval release for each colony of (A) Pocillopora damicornis and (B) Seriatopora hystrix based on $\mathrm{n}=1$ to 8 colonies $\mathrm{mo}^{-1}$ over 4 yr $(2003$, 2005, 2007, and 2008). Time (ordinate) is expressed as days in the lunar month relative to the new moon; seawater temperature (abscissa) is averaged by month. Data points indicate mean lunar day of larval release for each colony in study months cidence of peak larval release and neap tides in the summer may allow larvae to avoid internal tideinduced upwelling, and the associated downward thermal anomalies with perturbations of 2 to $10^{\circ} \mathrm{C}$ for several hours during spring tide in summer in Nanwan Bay (Lee et al. 1997, Jan \& Chen 2009). Upwelling-driven changes in the physical and chemical conditions of seawater - which can include low temperature and reduced $\mathrm{pH}$ and dissolved oxygen concentration (Jan et al. 2004, Jan \& Chen 2009, Rivest \& Gouhier 2015) - are likely to have negative consequences for reef corals, especially their larvae (Nakamura et al. 2011). These might include both physiological consequences arising from the large and frequent changes in water quality and reduced recruitment caused by the offshore transport of larvae released during periods of strong upwelling and spring tidal flows (Sponaugle et al. 2002). In other locations, upwelling has been shown to impede coral reproduction (Glynn et al. 1991, 2012) and recruitment (Rodríguez et al. 2009).

Peak larval release of $P$. damicornis and $S$. hystrix mainly occurred around the first quarter moon in summer. Furthermore, more than half of the larvae were released at around $28^{\circ} \mathrm{C}$ (Edmunds et al. 2011), which corresponds to lunar day 7 or 8 based on the empirical relationship between MLD of larval release and mean seawater temperature (Fig. 6). This timing of reproduction differs from that described for mass spawning of broadcasting corals in Nanwan Bay, which occurs after full moon, and peaks around the second quarter moon from May to September (Dai et al. 1992). The reason for a difference in larval release timing between brooding and broadcast species is not clear and could be an interesting direction for future research. The peak timing of larval release occurring around the first quarter moon and neap tide in summer may promote local retention of larvae on the natal reef. The local retention of larvae in summer is consistent with the highest recruitment of pocilloporids that occurs in summer months at Hobihu reef in Nanwan Bay (Soong et al. 2003, Kuo \& Soong 2010). This may also explain the abundance of adult colonies of $P$. damicornis and $S$. hystrix at Hobihu and Outlet reefs (Soong et al. 2003, Fan et al. 2006, Thachenko \& Soong 2010).

Understanding how species-specific factors and local habitat features - both individually and interactively - affect the timing and success of reproduction will improve our ability to predict how populations will respond to climate change (O'Connor et al. 2007, Byrne 2011, Moore et al. 2011, Reusch 2014, Bramanti et al. 2015). Empirical relationships be- 
tween temperature and larval release timing (Fig. 6) can help predict how reproductive timing might change under the influence of ocean warming. Moreover, by demonstrating that temperature is associated with the reproductive timing of reef corals (this study), and indeed can change it (Crowder et al. 2014), our findings reveal an important mechanism of bio-physical coupling through which seawater warming could modify synchronized ecological interactions such as those determining larval dispersal, recruitment, population dynamics, and community succession (O'Connor et al. 2007, Byrne 2011). Together, our results suggest that seawater temperature may regulate the lunar timing of larval release in brooding corals, and, therefore, increases in ocean temperature caused by climate change could disrupt the reproductive timing of reef corals.

Acknowledgements. This work was supported by grants from the National Museum of Marine Biology and Aquarium and the National Science Council, Taiwan (NSC 92-2621-B291-001, NSC 94-2621-B-291-001, and NSC 95-2621-B-291002-MY2 to T.-Y.F.) and the US National Science Foundation (OCE 08-44785, OCE 04-17412, and OISE 07-14434 to P.J.E.). Coral collection permits (KNP\#: 0962902896, 0972903180) were obtained from Kenting National Park Headquarters.

\section{LITERATURE CITED}

Ashkenazy Y, Fredj E, Gildor H, Gong GC, Lee HJ (2016) Current temporal asymmetry and the role of tides: NanWan Bay vs. the Gulf of Elat. Ocean Sci 12:733-742

Babcock RC, Bull GD, Harrison PL, Heyward AJ, Oliver JK, Wallace CC, Willis BL (1986) Synchronous spawnings of 105 scleractinian coral species on the Great Barrier Reef. Mar Biol 90:379-394

Baird AH, Guest JR, Willis BL (2009) Systematic and biogeographical patterns in the reproductive biology of scleractinian corals. Annu Rev Ecol Evol Syst 40:551-571

Bramanti L, Iannelli M, Fan TY, Edmunds PJ (2015) Using demographic models to project the effects of climate change on scleractinian corals: Pocillopora damicornis as a case study. Coral Reefs 34:505-515

Byrne M (2011) Impact of ocean warming and ocean acidification on marine invertebrate life history stages: vulnerabilities and potential for persistence in a changing ocean. Oceanogr Mar Biol Annu Rev 49:1-42

Carson HS, Lopez-Duarte PC, Rasmussen L, Wang D, Levin LA (2010) Reproductive timing alters population connectivity in marine metapopulations. Curr Biol 20:1926-1931

* Christy JH (2011) Timing of hatching and release of larvae by brachyuran crabs: patterns, adaptive significance and control. Integr Comp Biol 51:62-72

* Crowder CM, Liang WL, Weis VM, Fan TY (2014) Elevated temperature alters the lunar timing of planulation in the brooding coral Pocillopora damicornis. PLOS ONE 9: e107906

Cumbo VR, Edmunds PJ, Wall CB, Fan TY (2013) Brooded coral larvae differ in their response to high temperature and elevated $\mathrm{pCO}_{2}$ depending on the day of release. Mar Biol 160:2903-2917

Dai CF, Soong K, Fan TY (1992) Sexual reproduction of corals in northern and southern Taiwan. Proc 7th Int Coral Reef Symp 1:448-455

Edmunds PJ, Cumbo VR, Fan TY (2011) Effects of temperature on the respiration of brooded larvae from tropical reef corals. J Exp Biol 214:2783-2790

Fan TY, Dai CF (1999) Reproductive plasticity in the reef coral Echinopora lamellosa. Mar Ecol Prog Ser 190: 297-301

Fan TY, Li JJ, Ei SX, Fang LS (2002) Lunar periodicity of larval release by pocilloporid corals in southern Taiwan. Zool Stud 41:288-294

Fan TY, Lin KH, Kuo FW, Soong K, Liu LL, Fang LS (2006) Diel patterns of larval release by five brooding scleractinian corals. Mar Ecol Prog Ser 321:133-142

Glynn P, Gassman N, Eakin C, Cortes J, Smith D, Guzman H (1991) Reef coral reproduction in the eastern Pacific: Costa Rica, Panama, and Galapagos Islands (Ecuador). I. Pocilloporidae. Mar Biol 109:355-368

* Glynn PW, Colley SB, Mate JL, Baums IB and others (2012) Reef coral reproduction in the equatorial eastern Pacific: Costa Rica, Panama, and the Galapagos Islands (Ecuador). VII. Siderastreidae, Psammocora stellata and Psammocora profundacella. Mar Biol 159:1917-1932

*Harriott VJ (1983) Reproductive seasonality, settlement, and post-settlement mortality of Pocillopora damicornis (Linnaeus), at Lizard Island, Great Barrier Reef. Coral Reefs 2:151-157

Harrison PL (2011) Sexual reproduction of scleractinian corals. In: Dubinsky Z, Stambler N (eds) Coral reefs: an ecosystem in transition. Springer, Dordrecht, p 59-85

Harrison PL, Wallace CC (1990) Reproduction, dispersal and recruitment of scleractinian corals. In: Dunbinsky Z (ed) Ecosystems of the world, Vol 25: Coral reefs. Elsevier, Amsterdam, p 133-207

Hoegh-Guldberg O (1999) Climate change, coral bleaching and the future of the world's coral reefs. Mar Freshw Res 50:839-866

*Hoegh-Guldberg O, Mumby PJ, Hooten AJ, Steneck RS and others (2007) Coral reefs under rapid climate change and ocean acidification. Science 318:1737-1742

Jan S, Chen CTA (2009) Potential biogeochemical effects from vigorous internal tides generated in Luzon Strait: a case study at the southernmost coast of Taiwan. J Geophys Res Oceans 114:C04021

Jan S, Chen CTA, Tu YY, Tsai HS (2004) Physical properties of thermal plumes from a nuclear power plant in the southernmost Taiwan. J Mar Sci Technol 12:433-441

Jokiel PL, Ito RY, Liu PM (1985) Night irradiance and synchronization of lunar release of planula larvae in the reef coral Pocillopora damicornis. Mar Biol 88:167-174

Kerr KA (2015) Decreased temperature resulted in daytime larval release by the fiddler crab Uca deichmanni Rathbun, 1935. J Crustac Biol 35:185-190

Kerr KA, Christy JH, Collin R, Guichard F (2012) Reducing error in reproductive timing caused by temperature variation: interspecific differences in behavioural adjustment by fiddler crabs. Mar Ecol Prog Ser 459:1-16

Kuo KM, Soong K (2010) Post-settlement survival of reefcoral juveniles in southern Taiwan. Zool Stud 49:724-734

Lee HJ, Chao SY, Fan KL, Wang YH, Liang NK (1997) Tidally induced upwelling in a semi-enclosed basin: Nan Wan Bay. J Oceanogr 53:467-480 
Leichter JJ, Genovese SJ (2006) Intermittent upwelling and subsidized growth of the scleractinian coral Madracis mirabilis on the deep fore-reef slope of Discovery Bay, Jamaica. Mar Ecol Prog Ser 316:95-103

Lin CH, Soong K, Fan TY (2013) Hourglass mechanism with temperature compensation in the diel periodicity of planulation of the coral, Seriatopora hystrix. PLOS ONE 8: e64584

Mayfield AB, Fan TY, Chen CS (2013) Physiological acclimation to elevated temperature in a reef-building coral from an upwelling environment. Coral Reefs 32:909-921

McGuire M (1998) Timing of larval release by Porites astreoides in the northern Florida Keys. Coral Reefs 17: 369-375

Moore PJ, Thompson RC, Hawkins SJ (2011) Phenological changes in intertidal con-specific gastropods in response to climate warming. Glob Change Biol 17:709-719

Morgan SG (1996) Plasticity in reproductive timing in adjacent tidal regimes. Mar Ecol Prog Ser 139:105-118

Morgan SG, Christy JH (1994) Plasticity, constraint, and optimality in reproductive timing. Ecology 75:2185-2203

Morgan SG, White JW, McAfee ST, Gaines SD, Schmitt RJ (2011) Weak synchrony in the timing of larval release in upwelling regimes. Mar Ecol Prog Ser 425:103-112

Nakamura M, Ohki S, Suzuki A, Sakai K (2011) Coral larvae under ocean acidification: survival, metabolism, and metamorphosis. PLOS ONE 6:e14521

O'Connor MI, Bruno JF, Gaines SD, Halpern BS, Lester SE, Kinlan BP, Weiss JM (2007) Temperature control of larval dispersal and the implications for marine ecology, evolution, and conservation. Proc Natl Acad Sci USA 104: 1266-1271

Putnam HM, Edmunds PJ, Fan TY (2010) Effect of a fluctuating thermal regime on adult and larval reef corals. Invertebr Biol 129:199-209

Reusch TBH (2014) Climate change in the oceans: evolutionary versus phenotypically plastic responses of marine animals and plants. Evol Appl 7:104-122

Richmond RH, Hunter CL (1990) Reproduction and recruit-

Editorial responsibility: Charles Birkeland,

Honolulu, Hawaii, USA ment of corals: comparisons among the Caribbean, the Tropical Pacific, and the Red Sea. Mar Ecol Prog Ser 60: 185-203

Richmond RH, Jokiel PL (1984) Lunar periodicity in larva release in the reef coral Pocillopora damicornis at Enewetak and Hawaii. Bull Mar Sci 34:280-287

* Rivest EB, Gouhier TC (2015) Complex environmental forcing across the biogeographical range of coral populations. PLOS ONE 10:e0121742

* Roder C, Fillinger L, Jantzen C, Schmidt GM, Khokiattiwong S, Richter C (2010) Trophic response of corals to large amplitude internal waves. Mar Ecol Prog Ser 412: 113-128

Roder C, Jantzen C, Schmidt GM, Kattner G, Phongsuwan N, Richter C (2011) Metabolic plasticity of the corals Porites lutea and Diploastrea heliopora exposed to large amplitude internal waves. Coral Reefs 30:57-69

Rodríguez S, Alvizu A, Tagliafico A, Bastidas C (2009) Low natural repopulation of marginal coral communities under the influence of upwelling. Hydrobiologia 624: $1-11$

* Soong K, Chen MH, Chen CL, Dai CF, Fan TY, Li JJ, Fan H (2003) Spatial and temporal variation of coral recruitment in Taiwan. Coral Reefs 22:224-228

Sponaugle S, Cowen RK, Shanks A, Morgan SG and others (2002) Predicting self-recruitment in marine populations: biophysical correlates and mechanisms. Bull Mar Sci 70: 341-375

Tanner J (1996) Seasonality and lunar periodicity in the reproduction of pocilloporid corals. Coral Reefs 15:59-66

Thachenko KS, Soong K (2010) Protection of habitat types: a case study of the effectiveness of a small marine reserve and impacts of different habitats on the diversity and abundance of coral reef fishes. Zool Stud 49:195-210

* Villanueva R, Yap H, Montano M (2008) Timing of planulation by pocilloporid corals in the northwestern Philippines. Mar Ecol Prog Ser 370:111-119

Zar JH (1999) Biostatistical analysis. Prentice-Hall, Upper Saddle River, NJ

Submitted: July 15, 2016; Accepted: January 30, 2017 Proofs received from author(s): March 4, 2017 